\title{
A Case on Generative Art: Digital Poetry
}

\author{
Licia Calvi \\ NHTV University of Applied Sciences \\ Hopmanstraat, 1 \\ Breda, The Netherlands \\ calvi.l@nhtv.nl
}

\author{
Paul Buchanan \\ NHTV University of Applied Sciences \\ Hopmanstraat, 1 \\ Breda, The Netherlands \\ buchanan.p@nhtv.nl
}

\begin{abstract}
This paper investigates the notion of digital poetry as a form of generative art and explores the creativity design process behind it and the interaction with the audience/reader digital poetry enforces.
\end{abstract}

Digital poetry. Generative art. Creativity design process.

\section{INTRODUCTION}

This paper investigates the notion of digital poetry as a form of generative art and explores the creativity design process behind it and the interaction with the audience/reader digital poetry enforces.

"Digital" poetry is an umbrella term that encompasses several forms of e-poetry like visual poetry, media poetry, interactive poetry and generative poetry. Its ontological nature is still under discussion, although this term is mainly used to indicate the blurring of the boundaries between poetry tout court and new media, regardless of the forms these may take (Kac, 2007). As such, digital poetry originates from the avant-garde tradition and the Dadaism movement before it.

In (Calvi, 2004), a definition of the paradigm at play in adaptive hyperfiction had already been attempted by analysing three hyperpoems where some form of constraint-based rules were exploited to conditionally determine the reader's behaviour. This paradigm presupposed the existence of a distinction between a shallow text and a deep text, both of which represent the distinct space of activity of readers and authors, of the conditions and the rules defined by the artist/author to create the artistic experience that the audience will encounter to produce their own (reading) experience.

As for so many other digital art forms, the issue with digital poetry is also that of defining the function of both readers and authors (or spectators and artists) when reading or writing digital poetry and a discussion on how to assess critically (and to interpret) it. Is this a merely semiotic process, or is it instead one that, by questioning the specific aesthetics of digital media, also affects the notion of interactivity and offers an unusual approach to the design of the interaction it implies as well? And does this design only concern the way in which words and other signs (i.e., the hypermedia objects) are integrated into the poem and interact with one another (Memmott, 2003) or does it affect more deeply the specific role of the reader and their participation in the construction of the content and ultimately of meaning by interacting with that specific design? We clearly opt for this section approach. Memmott (2003), borrowing the term from Ulmer, calls this approach choragraphic because it looks at the poetry work as a whole "from interface design to interactivity, the written word and code" (Memmott, 2003).

In order to promote this choragraphic approach, the paper analyses a few digital poems. This analysis is intended to help us draw a common framework for the interpretation and understanding of generative poetry, to investigate the amount of experimental composition and the kind of creativity that it allows to authors and the explorative freedom for readers, to stretch and explore the limits both in the language and in the tool (i.e., the digital poem).

There is however no space in this paper for an extensive analysis, nor for an exhaustive comparison with existing theories of generative poetry.

\section{DIGITAL POEMS}

"Labylogue" (2000) is an example of such digital poems based on text generation. It is actually a virtual conversation space in the form of a labyrinth whose walls, made of text, change as a consequence of the visitor/reader's intervention when uttering words via a micro. Those words, that are supposed to represent an ongoing conversation with another reader/visitor located somewhere 
else $^{1}$ are the input for a new poem to be generated and projected on the labyrinth walls and corridors. There is a case of generativity and interactivity at play in this poem, where it is what the reader says that determines the text to be produced and portrayed on the walls. In this way, although it is the author who has to initialise this process, much escapes her power. Despite the somehow evident degree of unpredictability, this instability demonstrates however that deep text and shallow text are not totally separated entities, although ontologically different. It shows that communication between author and reader takes place, and that the place where it occurs is the poem itself (see next).

Ted Warnell is the author of several poems that are considered as "codeworks". Examples include "Poem by Numbers", "Viru2" and "Berlioz", all poems where the user's participation is essential and consonant to the unfolding and the construction itself of the poem. Such participation mainly takes the form of the user rearranging the interface/poem where either numbers (in "Poem by numbers"), code as text (in "Viru2"), and mixed email messages (in "Belioz") appear. They are also very aesthetical and transparent poems in the sense that the code is visible to the reader although not accessible (in the sense of modifiable) as such.

Finally, "Concatenation" (2000) combines, like in Warnell's poems, an aesthetically appealing poem with a minimalist interface and a combinatorial process to generate the text. The readability of this poem depends again on the reader's involvement and negotiation with the author. Readers can be merely passive, in which case the poem will restart, or active, either selecting or erasing certain words. All these actions cause the poem to evolve and reading to unfold.

\section{CHORAGRAPHY}

If we assume a choragraphic approach is the interpretative grid to understand and model digital, generative poetry, we need to find the missing link which connects code and text, deep and shallow text and accounts for the generativity and interactivity digital poetry puts on stage.

Figure 1 depicts this relationhip. There is a negotiation going on between author and reader which is explicit, concrete and functional to the final reading experience. This negotiation takes place at the interface, which is the poem itself. It does not really matter how this is designed and which objects it portrays. What matters is the reading experience, i.e., that the poem unfolds and in this

${ }^{1}$ This labyrinth is installed in 3 interconnected cities and allows visitors to communicate with each other. unfolding becomes readable allowing the reader to respond to the author's actions, to dialogue directly with her, to intervene in the construction of the content. This interactivity goes beyond coding (by the author) and decoding (by the reader) and it is more than simple user's participation in a creative process which is under the full control of the author. It is really an act of co-creation of content which occurs even before the creation of meaning.

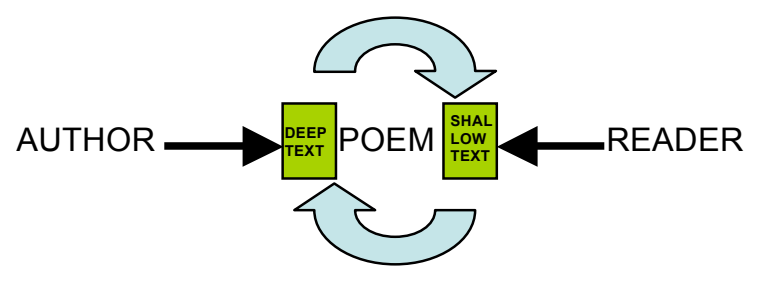

Figure 1: The author-reader relationship within a coragraphic approach to digital poetry

\section{CONCLUSION}

The paper has discussed the notion of digital poetry as an instance of generative art by analysing a few examples of poems where the reading experience is determined by the way in which reader and author communicate.

In doing so, we have derived a model to understand the creative process at the basis of the interaction between them which can account for the creation of content in the first place and of meaning afterwards. Creativity takes place at interface level where the negotiation between author and reader is staged and where the deep and the shallow text representing each of them are reconciled. The "choragraphy" of this approach guarantees a holistic understanding of poem creation.

\section{REFERENCES}

Benayoun, M., Barrière, J.-B. and. Balpe, J.-P. (2000) Labylogue.

http://www.benayoun.com/Labylogb.html (retrieved May, $\left.12^{\text {th }}, 2010\right)$.

Calvi, L. (2004) Adaptivity in hyperfiction. Proceedings of the fifteenth ACM conference on Hypertext and hypermedia, Santa Cruz, CA, 163170. ACM Press.

Geniwate and Stefans, B.K. (2000) Concatenation. http://collection.eliterature.org/1/works/geniwate g enerative poetry/concatenation2.html (retrieved May, 14 $\left.{ }^{\text {th }}, 2010\right)$.

Kac, E. (2007) Media Poetry: An International Anthology. Intellect Books, UK.

Memmott, T. (2003) Beyond Taxonomy: Digital Poetics and the Problem of Reading. ALLC/ACH 2003, The University of Georgia Athens, Georgia May 29-June 2, 2003, 97.

Warnell, T. http://www.warnell.com/ (retrieved May, $\left.13^{\text {th }}, 2010\right)$. 